\title{
Actores sociales y transformación de la estructura social ${ }^{1}$
}

\author{
CARLOS RUIZ ENCINA ${ }^{2}$
}

\begin{abstract}
Sumario
El cierre social de la elite, la clausura de una política que se observa a sí misma, la 'opacidad social' según la cual las conexiones entre lo social y lo político se hacen difíciles de precisar, el predominio de visiones reducidas de democracia, el incremento de las decisiones técnicas como contraparte del debilitamiento reduccionista de la política; son todos factores que se alimentan de -y a la vez potencian- el despliegue de la desigualdad en todos sus rostros. El Chile de hoy requiere que estos síntomas sean analizados en el marco de una vinculación -y no una divisiónde las transformaciones referidas a las cuestiones de la estructura social respecto a las problemáticas de los actores sociales. En caso contrario, una visión empobrecida de las mutaciones que se están produciendo será el único resultado.
\end{abstract}

Palabras clave: Cambio Social - Chile - Estructura Social - Actores Sociales

\section{Abstract}

The social enclosure of the elite, the closure of a type politics that only watches itself, the 'social opacity', according to which the links between the social and the political become hard to distinguish, the predominance of partial views of the democracy, the increase of the technical decisions as counterparts of the reductionist weakening of the politics; all of which are factors that are reinforced by -but they also act as encouragement of - the maintenance of inequality in all of its faces. It is required, in the present time of Chile, to analyze these symptoms within a frame that highlights the linkages - and not the divisions- of the transformations, relating to the issues of the social structure, with the constraints of social actors. If that is not the case, a poor picture of the mutations that are taking place in Chile will be the only outcome.

Keywords: Social change - Chile - Social structure - Social actors

\footnotetext{
1 Agradezco la colaboración de Giorgio Boccardo en la búsqueda y síntesis de discusiones desarrolladas en artículos anteriores.

2 Profesor del Departamento de Sociología de la Universidad de Chile. Investigador del Centro de Investigación en Estructura Social (CIES), patrocinado por la Iniciativa Científica Milenio (ICM).
} 
Revista de Sociolocía 21 / 2007 Chile Hoy

Facultad de Ciencias Sociales - Universidad de Chile

\section{Introducción}

Largo y prolífico, como pocos, es el debate que hay en las ciencias sociales acerca de la relación entre la estructura social y los actores sociales en un momento histórico determinado. Como se sabe sobradamente, los extremos van desde un estructuralismo momificante que concibe a los actores como mecánica consecuencia de la estructura y cuya conciencia ha de corresponderse con su posición dentro de ella, cosa que de no ocurrir constituye, simplemente, una situación de "falsa conciencia"; hasta, por el otro borde, la peregrina idea de que no existe ninguna relación entre actores y estructura, que la formación de los primeros se debe exclusivamente a elementos situados en el ámbito de la subjetividad, los que en algunas formulaciones llegan a divorciar completamente el universo del lenguaje de cualquier correlato material. Existen, como también se conoce de sobra, una profusa diáspora de elementos de carácter ideológico y político en estos extremos determinismos economicista y culturalista. No es el caso internarse aquí en esa reyerta que, en no poca medida, ha animado a nuestras ciencias sociales.

Entremedio, la dispersión de concepciones, elaboraciones, indagaciones y estudios es aún mucho mayor y variopinta. No en balde, quienes asumen la abigarrada y nunca bien premiada tarea de confeccionar los mapas han de ordenar todo este panorama, terminan muy seguido apelando -rendidos al fin- al prefijo neo a la hora de hacer las distinciones que registran. Por cierto, muchos de los elementos de las formulaciones originales -que a menudo resultan más caricaturizadas, que abordadas con una seriedad edificante- terminan mezclándose en eclecticismos pocas veces felices.

Aún cuando no es objeto de estas páginas, es imposible eludir el riesgo de adoptar un criterio básico, bajo el cual orientar el examen de las transformaciones más importantes de la estructura social chilena en las últimas décadas, y su relación con sus actores más relevantes. La transformación estructural chilena, honda y abrupta como pocas en la región latinoamericana (en donde resultan más graduales y progresivas), porta una drástica cuota de severa desestructuración de viejos actores. Lo anterior no significa, en ningún caso, que tal transformación opere sola, por encima de los actores; al contrario, es producida por estos mismos. El conflicto social que cobija la historia reciente es el teatro en el que se terminan dirimiendo las relaciones de poder que, en definitiva, han de primar sobre la dirección -o redefinición- del modelo de desarrollo, y con ello de las consecuencias que ello acarrea para aquellos grupos y clases sociales que han perdido incidencia en dichas relaciones de poder; aquellos que, por ejemplo, han sido expulsados de los procesos de construcción del Estado. De modo que la acción social, como tal, forma un elemento constitutivo de la estructura social, de sus transformaciones y la dirección que éstas asumen, al tiempo que dichas transformaciones inciden de modo fundamental en las posibilidades de constitución y proyección de los actores sociales. 
La recuperación de algunos elementos de la transformación de la estructura social de las últimas décadas, ha de marchar de la mano de una atención sobre las mutaciones acaecidas en el plano de los actores sociales, de sus rasgos y de los cambios en las relaciones que se establecen entre éstos.

\section{Nueva sociedad de las cenizas de un pasado arrasado}

Un primer aspecto en la dificultad de apreciar dinámicas y actores sociales relevantes en Chile hoy, tiene que ver con la desarticulación y pérdida de peso específico del viejo movimiento obrero, así como de importantes formas de organización y agrupación de intereses de las franjas más relevantes de las clases medias, como los colegios y las agrupaciones de profesionales o las asociaciones de empleados públicos. A partir de 1973 se inaugura tempranamente una primera dimensión coactiva bajo el régimen militar, directamente represiva, que interviene en tal dirección; ahí se suman también aquellas de proscripción y expulsión del espacio público que pronto se formalizan institucionalmente, como es el caso del Plan Laboral, que consagra la desarticulación de aquél movimiento obrero ligado a los partidos políticos y claramente inserto en la dinámica institucional. La actividad sindical se restringe a los marcos de cada empresa, clausurando las posibilidades de articulación interempresarial y sectorial, así como sus viejos términos de articulación política. Pero a corto andar, junto a la dimensión coactiva de la desarticulación que padecen los viejos actores sociales, se empieza a distinguir otra, de efectos acaso más profundos, que pone acento en la transformación de la estructura social, a partir del llamado giro neoliberal del modelo de desarrollo capitalista chileno.

Mucho se ha escrito sobre la jibarización de los viejos actores sociales y las categorías socioeconómicas asociadas a estos, y al momento de abordar la transformación neoliberal de la estructura social chilena, se pone énfasis en los llamados procesos de desestructuración, insistiendo en el socavamiento de las bases estructurales de dos actores sociales principales del período anterior: la clase obrera, a menudo más vinculada a los procesos industrializadores del aparato del Estado que al capital privado; y aquellas fracciones de las clases media también ligadas al empleo estatal, funcionarias, vinculadas más a una condición asalariada que a la pequeña propiedad, ideológicamente progresistas o, puesto en los términos del viejo lenguaje, desarrollistas.

Algunos estudios ${ }^{3}$ develan el proceso mediante el cual la vieja estructura social va

3 Véase respectivamente Martínez, Javier y Tironi, Eugenio, Las clases sociales en Chile. Cambio y estratificación, 1970-1980, Ed. Sur, Santiago, 1985; León, Arturo y Martínez, Javier, La estratificación social chilena hacia fines del siglo XX, en Chile en los noventa, C. Toloza y E. Lahera (editores), Ed. Dolmen y Dirección de Estudios de la Presidencia de la República, Santiago, 1998; Wormald, Guillermo y Torche, Florencia, Estratificación y movilidad social en Chile durante las últimas décadas del siglo XX, Informe de Investigación, Proyecto FONDECYT sobre Movilidad Social en Chile, No. 1010474, concurso regular 2001, Santiago, 2001. Una versión abreviada de las conclusiones de esta última investigación se puede encontrar en Wormald, G. y Torche, F., Estratificación y movilidad social en Chile, Series de la CEPAL, Santiago, 2004, o bien, extensamente comentada, en Atria, Raúl, Crecimiento y estratificación social: la paradoja del crecimiento y el caso chileno, en Revista CPU, No. 114, semestre 2, Santiago, 2004. 
quedando atrás, dando paso a un mapa social nuevo, marcado por la heterogeneidad más que por la emergencia de posiciones socio-estructurales capaces de ocupar en forma homogénea el enorme vacío dejado por el debilitamiento de esas viejas categorías. Se señala una drástica reducción de la vieja clase obrera producto de un proceso de desindustrialización que significa, en forma sucesiva, cursos de desalarización y reasalarización, durante los cuales la fisonomía del mundo asalariado se trastroca definitivamente bajo el nuevo rostro de la expansión del mundo de los servicios en detrimento de la vieja centralidad de la condición obrera. Tal terciarización de la fuerza laboral, junto a su feminización y a los cambios en las condiciones de asalarización, marcadas ahora por la informalidad y la flexibilidad laboral, configuran un panorama muy distinto al conocido hasta entonces. La extendida privatización de empresas estatales y el desmantelamiento de los enormes servicios públicos montados durante el período anterior, significan la desarticulación de las bases estructurales de existencia de las fracciones política e ideológicamente más influyentes de las clases medias. Su forzada "privatización", las reorienta al ingreso en empresas privadas consolidadas o bien a la aventura del emprendimiento forzoso en el mundo de la mediana y la pequeña empresa.

Esta desarticulación de grupos sociales significa no sólo el desmembramiento de los actores ligados a ellos, sino también el desplazamiento de los códigos de interpretación de la sociedad, las mentalidades y el sentido con que se apreciaban ciertas instituciones y procesos sociales. Pues, en base a esas categorías y actores es que se comprendían procesos como la urbanización, la expansión del sistema educativo, la ampliación del acceso a las comunicaciones, la extensión de la ciudadanía política y la participación social, entre otros.

Se consigna además el mejoramiento más rápido, ya entrados los años noventa, de los ingresos laborales de las categorías de trabajadores independientes en comparación con las posiciones asalariadas, en un contexto en el cual se reconocen como más reducidas las posibilidades de movilidad social efectiva. Junto a la extensión de la terciarización de la fuerza de trabajo, concita atención la burocratización del trabajo asalariado bajo la nueva organización privada, una suerte de "burocracia moderna de servicios privados" de fuerte expansión, internamente bastante diferenciada y no reductible a la imagen de las cúpulas tecnocráticas.

Una caracterización que, por cierto, alcanza más precisión y nitidez en los extremos de la pirámide social, mientras que en el sector intermedio de la distribución tiende a clasificar a los individuos con criterios más difusos y a menudo superpuestos. Las categorías intermedias aparecen como una zona gris en la comprensión del perfil y la dinámica de la estructura social, lo que reanima la disyuntiva acerca de la extinción de las clases sociales o el surgimiento de otras nuevas. Debido al carácter extremada- 
mente dinámico -inestable, si se quiere- de los segmentos medios, se aprecia cierta tendencia a la polarización social en su interior, dada la existencia de categorías que experimentan una movilidad social ascendente mientras que otras, más numerosas, son empujadas en dirección opuesta. Este hecho dirige las preguntas a la efectividad de las dinámicas meritocráticas y de expansión de las oportunidades, y anima desde esta perspectiva la inquietud por la equidad.

\section{Crecimiento con desigualdad}

Desde 1997 en adelante, hemos sido testigos de un debate más claro acerca del rumbo que sigue el desarrollo social del país, a partir de las transformaciones económicas, políticas y culturales experimentadas en las últimas décadas. Reaparece porfiadamente en los análisis el cuestionamiento acerca de si ¿Chile es un país moderno?, y con ella todas las implicaciones que sabidamente se derivan.

Entre las conclusiones más reiteradas acerca de las tendencias que caracterizan el cambio que experimentó la sociedad chilena en el período 1992-2002 aparecen básicamente cuatro ${ }^{4}$. La primera indica un aumento sostenido del bienestar de la población, fundado en el acceso a nuevos bienes, servicios y oportunidades; ello se considera indicativo de un aumento de la calidad de vida y del bienestar general de la población. La segunda plantea una marcada tendencia a la integración o la inclusión de los sectores más desfavorecidos a ciertos beneficios del progreso, lo que se considera un efecto no sólo del desenvolvimiento del mercado sino de la acción efectiva de políticas públicas orientadas a la construcción de mayores niveles de equidad en la sociedad. La tercera releva la tendencia hacia un mayor asentamiento o estabilidad geográfica de la población como resultado de la detención de los antiguos procesos migratorios campo-ciudad, curso que sería ayudado por una movilidad educacional en pleno proceso de crecimiento. Por último, se señala la existencia de una mayor heterogeneidad o diversificación social, la cual se expresaría principalmente en la multiplicidad de las formas de familia.

Otras investigaciones, en cambio, llaman la atención sobre la paradoja abierta por los grados de desconfianza e inseguridad que acompañan al proceso de cambios considerado. En 1998 un informe del PNUD insistía al respecto, a partir de registros realizados precisamente en los momentos de máxima expansión que cobija el ciclo

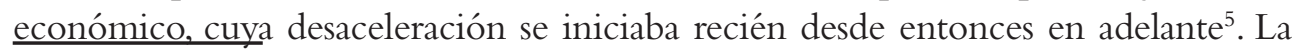
$4 \quad$ Véase por ejemplo Una visión de Chile a partir de los datos del Censo 2002: ¿cuántos y cómo somos los chilenos?, editado por el INE; o bien Cuánto y cómo cambiamos los chilenos. Balance de una década. Censos 19922002, de varios autores, editado también por el INE y la Presidencia de la República, como parte de los Cuadernos del Bicentenario. En particular en este último, véase de Eugenio Tironi el trabajo ¿Es Chile un país moderno?.

5 Véase el estudio Desarrollo humano en Chile: Paradojas de la modernización, Programa de las Naciones Unidas para el Desarrollo (PNUD), Santiago de Chile, 1998. Es más, el Informe de Desarrollo Humano elaborado por el PNUD precisamente en el mismo año 2002, registra una extendida desconfianza de la población chilena frente al desarrollo económico experimentado. En términos de valoración al respecto, un elevado 59\% estima que "es más 
"paradoja" consiste en el hecho que, a pesar de que el modelo de desarrollo vigente puede mostrar logros evidentes en materia de indicadores económicos, en la sociedad chilena se producen grados significativos de desconfianza, tanto en las relaciones interpersonales, como en los sistemas institucionales que inciden en la seguridad colectiva, como son los de salud, previsión, trabajo y educación.

Como se ha señalado en otras ocasiones ${ }^{6}$, el principio de explicación de esta problemática ha tratado de encontrarse en las tensiones que genera el proceso de modernización. Max Weber señalaba que un despliegue de una racionalidad de carácter puramente instrumental, o sea de una adecuación mayormente formal de medios a fines, pone en peligro una racionalidad sustantiva en donde, tanto los medios como los fines son elegidos de acuerdo a valores. En el informe del PNUD se hace mención a una tensión entre un proceso de modernización, más ligado a la primera dimensión señalada, y un proceso de subjetivación que correspondería a la segunda de ellas. Pero además de ello, un segundo eje de tensiones en la modernización en curso se constituye entre los procesos de diferenciación social y los procesos de integración. Estos procesos y tensiones afectan tanto a las personas como a los grupos sociales y a las instituciones, éstos últimos más dificiles de considerar a partir de la estructura de los registros censales centrados en las personas. No obstante, es la perspectiva de los grupos sociales -y con ello sus cursos de formación o desarticulación- la que permite establecer en mayor medida para quienes resulta más exitosa la economía, así como precisar también el carácter social de la insatisfacción.

Específicamente en torno a estos datos censales y su comparación con los que entregaba la anterior edición del censo, en 1992, al hacer un balance de la década Tironi ${ }^{7}$ sostiene que estos cambios tienen que ver con el ingreso pleno de la sociedad chilena en un proceso de "modernidad avanzada" o posmodernidad, expresado principalmente en las dimensiones de movilidad social que mostraría, de aguda mejora en las condiciones de vida y del bienestar general de la población y en los avances sustantivos que este proceso produciría en términos de inclusión o integración social. Se trata, en definitiva, de los resultados de un curso que define como de "redistribución silenciosa", efecto que -aunque no precisa- habría que atribuir a la acción de un mercado crecientemente determinante sobre el destino del grueso de la población chilena. Sin embargo, como señalan expresamente buena parte de los propios autores cuyos análisis emplea Tironi, los resultados censales no permiten tales extrapolaciones, como la conclusión tajante en términos de la existencia de significativos procelo que hemos perdido", al contemplar los cambios ocurridos en Chile, mientras que sólo un 36\% estima lo contrario. Véase el Informe de Desarrollo Humano en Chile 2002, PNUD, Santiago de Chile, 2002.

6 Véase Faletto, Enzo, Panorama Social, en Revista Análisis del año 1998, Sociedad, Política y Economía, Departamento de Sociología, Universidad de Chile, Santiago, enero, 1999.

$7 \quad$ Véase Tironi, op. cit.

8 Es clara la semejanza con aquella caracterización, de "revolución silenciosa", que hace Joaquín Lavín en los años ochenta al alabar los logros del gobierno militar; a la que entonces se oponía el propio Eugenio Tironi, reclamando por los "silencios de la revolución". 
sos de movilidad social, elevación sustantiva y generalizada de la calidad de vida y un curso de inclusión o integración social.

Ahora bien, puede que en el último período la economía viva su mejor momento en mucho tiempo, pero aparejado a este fenómeno, las agudas desigualdades permanecen y hasta se extreman, y dentro de ello el desempleo aparece como un porfiado componente. Las cifras de la creación de empleos terminan por ceder ante otro hecho concomitante: la destrucción de empleos producto de una muy alta rotación que afecta al mercado laboral o, si se quiere, la gran inestabilidad que afecta a los empleos, lo que redunda en su corta duración. Precisamente en medio de la discusión de los mentados resultados censales, la Dirección del Trabajo estimaba que entre octubre de 2002 y abril de 2003, el 93\% de las personas que fueron contratadas no duraron más de un año en sus nuevos puestos de trabajo, de acuerdo a la información proporcionada por los registros del seguro de desempleo. La misma fuente precisaba además que las firmas de mayor tamaño sólo contrataban al 25\% de sus empleados en forma indefinida, mientras que al interior de las PYMES este número se empinaba sobre el 50\%. Por cierto, tan alto porcentaje de relación directa entre nuevos contratos y despidos muestra que el sistema laboral chileno no adolece de inflexibilidad, como plantean varios economistas en los últimos años, a propósito del combate a la pobreza y la iniquidad.

Hace no mucho, un estudio de la Universidad de Chile registraba el hecho que el apellido, el colegio y la comuna donde se vive constituyen factores que determinan los salarios a los que puede aspirar un chileno9. El estudio logró establecer que el orden de magnitud de la brecha del origen social en los ingresos es casi el doble de la brecha de género, y cerca de tres veces la brecha de raza y de apariencia personal. El origen socioeconómico resulta, pues, más importante que un buen desempeño académico en la universidad para tener mayores ingresos en el futuro. Entre las causas del fenómeno sitúa la discriminación y la productividad laboral vinculadas al origen socioeconómico. Ello porque las empresas privilegian la contratación de profesionales con acceso a redes sociales que no están determinadas necesariamente por sus méritos académicos, pero que tienen un importante valor económico.

Los propios grados de concentración del poder empresarial alcanzan una magnitud que se constituye en un factor dualizante dentro de la economía, separando a un sector claramente oligopólico de otro que se puede entender realmente inmerso en efectivas situaciones de competencia. Mientras el primero acapara-muchas veces a partir de disposiciones políticas- las esferas más dinámicas de la economía en cuanto a posibilidades de acumulación y crecimiento, y lo hace sin mayor capacidad para dinamizar al grueso de la economía interna; el segundo, en cambio, se desenvuelve

9 Nuñez, Javier y Roberto Gutierrez, Classism, discrimination and meritocracy in the labor market: the caso of Chile, Facultad de Economía, Universidad de Chile, Santiago, 2004. 
en condiciones mucho más próximas a aquellas que venera el discurso de la libre competencia, y genera la inmensa mayoría del empleo en nuestro país. Ya el propio Adam Smith llamaba la atención sobre la necesidad de distinguir entre empresa privada y mercado como tal, advirtiendo sobre un equívoco que está en el fondo de la llamada ideología neoliberal. En definitiva, la excesiva concentración empresarial atenta en contra de la propia libre competencia. Dificulta además la regulación del Estado, el manejo equilibrado del mercado y la presión por mejores salarios del personal. La alta concentración económica existente en Chile no sólo es profundamente injusta, sino que genera también una enorme vulnerabilidad y afecta la capacidad de reactivación de la economía.

Cabe entonces interrogarse: ¿crecen más rápido las sociedades menos igualitarias que las más igualitarias? En estos años se ha repetido la idea de que Chile puede llegar a ser un país desarrollado en el año 2010, cuando celebre su bicentenario. Pero, como ya se ha dicho, nuestro país se distancia de los desarrollados no sólo por su nivel de ingreso, sino también porque presenta un elevado grado de desigualdad en su distribución, lo que se traduce en que cerca de $1 / 5$ de su población se encuentra aún en condiciones de pobreza absoluta y que una fracción no inferior a $40 \%$ obtiene ingresos extremadamente bajos, lo que la hace muy vulnerable frente a ciclos económicos recesivos. En este sentido, la idea de que Chile podría ser un país desarrollado en los próximos 10 años no encuentra sustento alguno en los registros sobre el nivel y distribución del ingreso actual y aquellos que se alcanzarían bajo hipótesis optimistas ${ }^{10}$. Y lo complejo de este problema no está ni tanto ni tan sólo en las dimensiones que adquiere la pobreza y la indigencia, sino en las proporciones que alcanza la desigualdad propiamente tal. Más que la escasa participación del estrato bajo en la distribución del ingreso, lo que diferencia más nítidamente a la distribución del ingreso de los países latinoamericanos, y de Chile especialmente, en comparación con los países de la OCDE, es la muy elevada fracción de ingreso total que capta el grupo más rico de la población. En otras palabras, el rasgo distintivo de la desigualdad hoy apreciable en la sociedad chilena, está situado en los extremos niveles de concentración del ingreso que registra.

Ello tiene que ver con la orientación que asumen las transformaciones económicas, políticas y socioculturales en las últimas décadas en nuestro país, lo que remite a las relaciones de fuerza y de poder que se establecen entre los distintos grupos y sectores sociales. De hecho, la desigualdad en la distribución del ingreso en Chile se arrastra a través de muchos años, pero comienza a empeorarse aceleradamente a partir de 1973. En el período comprendido entre 1990 y 2003, con el advenimiento de la democracia, los principales indicadores de la distribución del ingreso autónomo no

10 Así lo sostiene Arturo León en un trabajo realizado para la CEPAL, titulado ¿Será Chile un país desarrollado cuando celebre el bicentenario? Allí se examinan distintas variantes bajo un sistema de simulaciones, descartando por esta vía toda posibilidad. 
cambiaron significativamente, aunque en la primera mitad de la década se produce un leve mejoramiento en los deciles inferiores debido a los programas sociales y los subsidios monetarios.

En suma, Chile muestra una inequitativa distribución del ingreso, lo que no ha cambiado de modo significativo con las políticas sociales orientadas a la disminución de la pobreza.Aunque, tras la aplicación fiscal de transferencias monetarias y no monetarias, se observa una mejoría en los segmentos más desposeídos, en la práctica no se han remediado efectivamente las causas estructurales de la dispersión distributiva, convirtiendo aquellas transferencias en medidas paliativas de alcance inmediato, que aumentan la dependencia económica del Estado de franjas crecientes de la población.

La situación actual contiene basamentos seculares, pero por primera vez en la historia del país existe un consenso en las élites dirigentes en temáticas como la focalización del gasto, el superávit estructural del 1\% y la legalidad constitucional vigente a favor de las rentabilidades empresariales, a través de los incentivos a la inversión nacional y extranjera. No obstante, la polémica se ha reabierto debido a que organismos internacionales, tales como el PNUD, la OCDE y el Banco Mundial, verifican que a partir de 1973 la distribución del ingreso ha empeorado y que, pese a la estabilidad macroeconómica, el control inflacionario y la habilidad comercial del país, la iniquidad y las debilidades del sistema de seguridad social deberían atenderse con prioridad.

A nivel de la vida social se manifiesta la iniquidad que produce la transformación económica, incidiendo en la redefinición de la estructura social, en la conformación de la estructura de clases y grupos sociales. Esto afecta los procesos de integración social y de socialización, y debilita a las viejas formas e instituciones encargadas de ello: la moral, el derecho, la familia y la educación.

De acuerdo a algunos análisis acerca del carácter de las transformaciones experimentadas por las sociedades chilena y latinoamericanas en general, en las últimas décadas, las formas más relevantes de diferenciación social están dadas, en términos históricoconcretos, principalmente por aquella que produce la división social del trabajo en términos de clases y grupos sociales; por la que producen las "condiciones de vida", relativizando o agudizando las diferencias provenientes de la división social del trabajo; por el grado y tipo de inserción en los sistemas de socialización; y por las capacidades y posibilidades de cada grupo de conformación de instituciones asociativas que permitan la agrupación de intereses y la formación de identidades colectivas, lo que determina las posibilidades de la acción colectiva y su incidencia en el proceso social y político ${ }^{11}$. Éstas últimas, evidentemente, aluden a las relaciones de fuerza y de poder que existen en la sociedad, y con ello a las formas del dominio y sus grados de

11 Para más detalles, véase Baño, R. y Enzo Faletto, Transformaciones sociales y económicas en América Latina, Cuadernos del Departamento de Sociología, Universidad de Chile, Santiago, 1999. 
efectividad. De modo que, las diferencias sociales no son un efecto mecánico de los cambios al nivel de la economía, sino en gran medida, incluso éstos últimos, se deben a la dirección que unos grupos en tensión con otros le imponen a la transformación de la sociedad como resultante de sus grados de poder, así como de los menguados grados de poder de las restantes fracciones y grupos sociales.

Como es apreciable, el de la desigualdad no es un problema puramente económico, sino que comporta efectos sociales, culturales y políticos. En términos de esto último, hay que consignar que en Chile el 31\% de la población se considera no demócrata, lo que remite al hecho conocido que las facultades democráticas pierden legitimidad cuando no pueden resolverse las desigualdades sociales ${ }^{12}$.Y los índices de delincuencia se tornan preocupantes, con lo que la anomia y la falta de cohesión social comienzan a ser parte de las respuestas de la ciudadanía.

Una distribución del ingreso muy desigual hace más dificil reducir la pobreza, al impedir que las personas de menores recursos tengan los medios para realizar sus proyectos, limitando sus oportunidades y capacidades para optar a niveles de educación, salud y habitabilidad de calidad, lo que genera una fuerza de trabajo segmentada que tendrá enormes dificultades para enfrentar los desafios de la competencia internacional. Así, la desigualdad impide el propio proceso de desarrollo y desacelera el crecimiento económico. No tiene sentido, pues, pensar en crecer sobre la base de salarios bajos. Por eso, romper el círculo vicioso de la pobreza y la indigencia es un objetivo no sólo ético, sino fundamental en términos de crecimiento y estabilidad. La distribución del ingreso debe gran parte de su relevancia a la medida en que refleja sociedades no integradas en caso de resultar muy inequitativa.

\section{Lo social y su opacidad}

Otro fenómeno reciente en la historia chilena e indicativo de la especificidad de su actualidad, es el retroceso que registra el sentimiento de identificación social. Por un lado, la sociedad chilena ha experimentado una enorme reorganización de los modos de diferenciación y jerarquización sociales. Por otro, puede decirse en cierta forma que la política se "des-sociologizó" de un modo claro ya a partir de los años noventa. Por unas y otras razones, esa pérdida de fuerza de las identidades colectivas se ha traducido en una extendida sensación de una mayor opacidad social ${ }^{13}$, en donde los actores y las dinámicas sociales se han tornado prácticamente imperceptibles. Es más, tal dificultad de percepción de los modos de diferenciación social más relevantes y sus efectos concretos, de las dinámicas sociales y sus actores, pasa a constituirse en sí $12 \quad$ Véase Encuesta Latinbarómetro 2001.

13 Ocupo la expresión "opacidad social" en el sentido en que recurre a ella discusión social francesa reciente, la cual, a pesar de sus particularidades, me parece adecuada para referir ciertos fenómenos propios de la situación chilena. Al respecto pueden verse entre otros Castel, Robert, La metamorfosis de la cuestión social, Ed. Paidós, Bs. As., 1997, y Fitoussi, Jean-Paul y Rosanvallon, Pierre, La nueva era de las desigualdades, Ed. Manantial, Bs. As., 1997. 
misma en uno de los rasgos más distintivos de la sociedad chilena contemporánea. Es esa su 'opacidad'.

Ahora bien, el fenómeno de la opacidad social no se puede atribuir únicamente a los cambios estructurales, dado que la magra visibilidad que envuelve a gran parte de las dinámicas sociales, tiene que ver también con los cambios que experimenta la esfera política. Hoy su rasgo más distintivo, en relación a la fisonomía que adopta durante la mayor parte del siglo pasado, está en el hecho que deja de expresar en forma clara a vastos sectores de la sociedad. Se trata de un cambio del carácter social de la política determinado por un acentuado elitismo, que diluye el acceso y los controles de gran parte de la sociedad sobre dicha esfera. Como se ha señalado muchas veces, tal transformación redunda en una autonomización de la esfera política, que colabora en forma gravitante a la invisibilidad de las diferentes categorías sociales.

Tal orientación de la transformación de la política constituye una resultante de las relaciones sociales de fuerza más determinantes en la historia inmediata. Se trata del carácter antipopular de la ofensiva dictatorial, pero también de la proyección de sus rasgos fundamentales en la etapa democrática actual. Ajena a las demandas sociales surgidas de las regresiones en las condiciones de vida que acarrea para vastos sectores la transformación neoliberal, la transición a la democracia se reduce mayormente a los aspectos administrativos y procedimentales de la política. La llamada "deuda social", alusiva a la pérdida de derechos sociales y económicos por parte de los sectores populares y medios bajo la dictadura, es la gran ausente en dicha transición.

Las reformas laborales y tributarias impulsadas, definen tempranamente la proyección del carácter antipopular del modelo de crecimiento heredado ${ }^{14}$. De esta forma, se consagran las desigualdades sociales extremadas bajo el régimen militar. Dos objetivos se reiteran como fin en sí mismos ante las demandas sociales: el argumento tecnocrático de la "mantención de los equilibrios macroeconómicos" y la estabilidad de la "transición". El ideologismo que permea al discurso político hace abstracción del carácter y los efectos sociales diferenciados de las políticas impulsadas. Con ello contribuye de forma gravitante a una opacidad social.

Sin el contrapeso de los actores sociales excluidos del pacto de la transición, la política se hace más elitista. Debuta desde La Moneda el llamado "partido transversal",

$14 \quad$ Se establece un incremento del Impuesto a la Renta del 10 al 15\% (muy debajo de los estándares internacionales, que en países industrializados superan holgadamente el 30\%) y del IVA del 14 al 16\%, trasladando el grueso del alza impositiva a la mayor parte de la población, legitimando además la estructura distributiva. Por otra parte, las nuevas leyes laborales proyectan y perfeccionan las viejas disposiciones del Plan Laboral heredado: un sindicalismo reducido al ámbito de la empresa, condiciones laborales flexibles y la desaparición de los viejos derechos laborales, amplios márgenes de manejo empresarial frente a la fuerza de trabajo, prescindencia estatal en materia de regulación de las relaciones laborales, entre otros aspectos. El empresariado consideró a ambas reformas como parte de un solo paquete: la proyección del modelo económico y social heredado, ahora refrendado por las modalidades del nuevo sistema político. 
tejiendo un importante red de poder político y social. Junto con ello, el alto grado de presidencialismo que establece la Constitución de 1980, antes criticado, es aprovechado por las nuevas autoridades. Ello hará eclipsar al Congreso y los partidos políticos en el desarrollo de las relaciones y acuerdos con los restantes actores de la trama del poder. Si bien el Estado ha disminuido producto de la transformación neoliberal, el gobierno es fuerte en el sentido aquí considerado, los actores sociales -con excepción del gran empresariado- son débiles y marginales y los llamados poderes fácticos aparecen como omnipotentes. La marcada ausencia de actores sociales gravitantes, con la excepción ya hecha, otorga gran centralidad a una "política de los acuerdos" de escasa transparencia y reducidos espacios de actividad, lo que hace que incluso los partidos políticos aparezcan relegados a un segundo plano en la toma de decisiones y sufran un creciente desprestigio.

Los partidos pierden su carácter representativo de intereses sectoriales, deviniendo en partidos "nacionales" bajo una orientación más integrativa que conflictiva, abocada a contribuir a la legitimación del poder. De ahí que la tendencia a los acuerdos entre fuerzas políticas que antes resultaban enfrentadas en virtud de las representaciones sociales que asumían. Una integración y autonomía creciente del sistema partidario que no encuentra una contrapartida en niveles de organización social capaces de presionar por sus demandas. Los sectores más organizados pierden incidencia en el proceso político, como las organizaciones sindicales, pero también aquellas capas medias antes lideradas por el sindicalismo de empleados públicos y las agrupaciones de profesionales liberales; sólo el empresariado gana fuerza como grupo de presión.

En cambio, crece la importancia de la tecnocracia y los medios de comunicación de masas en la nueva escena política. El consenso dominante sobre el modelo económico permite sustraer la definición de políticas económicas del debate político, lo que otorga a estas tecnocracias un lugar privilegiado en la adopción de tales decisiones.Y la incidencia de los medios de comunicación en la formación de opiniones aumenta en la medida en que se debilitan las viejas identidades sociales y políticas. Esto y la extrema concentración de la propiedad de los medios de comunicación acrecienta su importancia en la creación de opinión pública, y permite que no se reduzcan meramente a expresarla.

La participación electoral deviene expresión central de la democracia, reduciendo el ideario democrático a la realización de votaciones. El énfasis puesto en convertir al sistema de partidos y el ejercicio electoral en un mecanismo de legitimación, termina por debilitar su función de representación social. Así, el fortalecimiento del sistema político se concibe en realidad a través de su autonomización de lo social, con lo cual los partidos políticos se debilitan al desvanecerse su vieja función de promoción de la agrupación de intereses sociales. Todo ello debilita los mecanismos representativos de 
la política, reduciéndola a la administración de los consensos ya construidos. De este modo, tal naturalización de las decisiones políticas, produce en forma importante la anotada opacidad social al invisibilizar el carácter social de dichas decisiones.

La situación general del poder en la sociedad se expresa así en forma distorsionada en el sistema político formal. El llamado "circuito extra-institucional del poder", integrado por el gran empresariado, los conglomerados de los medios de comunicación masiva, la iglesia y las fuerzas armadas, alcanza una enorme determinación sobre las políticas económicas, la dirección cultural de la sociedad, las relaciones internacionales, así como sobre la regulación de importantes espacios de base de la sociedad. Tal elitismo representa una rígida brecha entre lo social y lo político; convirtiendo a la política en un asunto de élites que relativiza la incidencia de las instituciones formales, como el parlamento y el sistema de partidos.

Importantes funciones estatales se sustraen de la política abierta, muchas de las cuales se presentan ideológicamente como "técnicas" y "apolíticas". El Estado, más allá de conservar el monopolio de la fuerza como último recurso de dominio, se abstiene de regular muchos ámbitos de relaciones sociales, como ocurre en el caso de las relaciones laborales. Tal régimen de prescindencia estatal en la regulación de los conflictos sociales, responde a la decisión de no volver a las viejas formas del Estado de Compromiso, que subyace en el pacto de la transición. La modalidad vigente de dominación no apuesta a un Estado que impulse y maneje un pacto social, sino a uno que mantenga la atomización y la marginación heredadas. Los basamentos de la actual gobernabilidad democrática se sitúan así en la mantención de la desarticulación social heredada del período autoritario.

Producto de esto se genera una disparidad entre la institucionalidad democrática y la política formal, de un lado, y las formas de regulación de las relaciones sociales a nivel de la base de la sociedad, de otro; ya que al cerrarse el acceso popular a los procesos de construcción del Estado y desarticularse las viejas formas de relación entre los partidos y algunos sectores populares, se despolitizan las relaciones sociales que anidan en la base de la sociedad. Los sectores populares y vastos sectores medios son excluidos de la política, lo que limita su capacidad de proyección hacia el Estado. La transformación política expulsa del espacio público a los sindicatos, núcleos de partido y "organizaciones" nacionales de masas, abriendo espacio para una recuperación de la vieja tradición carismática de las élites, así como la dependencia clientelística de "la masa".

Restringida así la política a dilemas de gestión a partir de la naturalización de las definiciones adoptadas, y reducida la lógica representativa a la apelación a un ciudadano con abstracción de su condición social, se desdibuja en definitiva el carácter social de la dirección del proceso histórico. Hoy los grados de determinación del gran em- 
presariado sobre la política contrastan fuertemente con el carácter que ésta detenta a lo largo de gran parte del siglo pasado, especialmente desde los años cincuenta en adelante, a partir de la irrupción de las masas populares en la política institucional. Lo que tenemos hoy como política es el producto de la reversión de ese largo proceso histórico.

De esta forma, la desarticulación de las viejas condiciones de constitución de la acción colectiva y de los sistemas de relaciones sociales que caracterizaron a las instituciones ubicadas en la base de la sociedad, dificulta la continuidad o la reanimación de la mayor parte de las formas de organización y de incidencia que tuvieran durante casi medio siglo los sectores subalternos. Esta situación determina una baja posibilidad de constitución de formas de acción colectiva y, como tal, de incidencia en el proceso social y político.

En este sentido, es necesario tener en cuenta las consecuencias que arroja el proceso de terciarización y expansión del sector de los servicios, y la medida en que constituye un sector de la sociedad relativamente nuevo en muchos aspectos, al tiempo que carente de expresión social y política. En no pocos casos se mezclan en su interior franjas medias de restringidas posibilidades de ascenso social, excluidas de las esferas más dinámicas del modelo de crecimiento vigente. Mucho de lo que se ha interpretado a menudo como nuevas formas de malestar social parece estar relacionado con este sector de la sociedad, especialmente con sus fracciones más calificadas.

Ya en la década pasada Norbert Lechner plantea con cierta insistencia una preocupación por algunos de estos malestares al aludir a las "paradojas de la modernización"15. Como antes se anotó, entonces se apuntaba a la tensión entre modernización y subjetividad producto de la orientación de las transformaciones acaecidas en la sociedad chilena.Aunque esto no constituye una novedad en la discusión sociológica, en Chile tendrá un efecto político importante, e intelectualmente consigue reabrir ciertos espacios en las ciencias sociales que recuperan su viejo espíritu crítico originario.

La continuación del proceso de terciarización de la fuerza de trabajo, la atención que comienza a concitar la burocratización del trabajo asalariado bajo la nueva organización privada, la fuerte y sostenida expansión de una suerte de "burocracia moderna

15 Este Informe de Desarrollo Humano en Chile del PNUD, ya mencionado y titulado así precisamente, realiza bajo la dirección de Lechner un diagnóstico de la sociedad chilena en el que se llama la atención sobre los malestares de importantes sectores medios con la modernización neoliberal. Aparecido en 1998, llega en un momento de incertidumbre ante el patrón de crecimiento vigente, y de conatos internos dentro de la alianza oficialista que, entonces, se conocen como una división entre sectores "autoflagelantes" y "autocomplacientes". Véase PNUD, Desarrollo humano en Chile: Las paradojas de la modernización, Santiago, 1998. Lechner, por cierto, retoma aquí su incursión en el debate sobre el Estado y el mercado de fines de los años ochenta e inicios de los noventa, no tanto en términos económicos como en cuanto a una preocupación por el orden social, insistiendo en que éste no descansa en los mecanismos del mercado ni de un sistema político que opera al margen de la sociedad. Para una discusión de estos planteamiento puede consultarse también Faletto, Enzo y Ruiz, Carlos, La modernización puesta en duda, en Revista Análisis del año 2000. Política, Economía y Sociedad, Departamento de Sociología, Universidad de Chile, Santiago, enero, 2001. 
de servicios privados" parecen estar vinculadas a estas preocupaciones. Las discusiones del pensamiento social que desarrollan la noción de "trabajo inmaterial" y se ocupan de su centralidad para las modalidades actuales de valorización del capital, apuntan a lo mismo. De la mano de la idea de la existencia de una relación entre las formas cambiantes de resistencia social y las transformaciones de la producción económica y social, plantean la posibilidad de constitución de una nueva cultura política y el desarrollo de nuevas formas de organización y conflicto en las clases subalternas. Sin embargo, pese a lo sugerente de estas formulaciones, suelen extrapolar el grado de avance de transformaciones aún en curso, restándole importancia a los grados de heterogeneidad existentes y, en particular, al hecho que muchas de las viejas categorías sociales no desaparecen del todo, imprimiéndole gran complejidad a los problemas relativos a la generalización de intereses, lo que determina procesos mucho más complejos para la acción política. .

Por otra parte, la experiencia regional no parece indicativa respecto del desarrollo social chileno. Las experiencias actuales de los movimientos sociales más activos en América Latina resisten una transformación social, económica e institucional que, en Chile, ya se ha consolidado y poco pueden asociarse a ello entonces los sujetos que comienzan a asomar en las condiciones locales, propias de una situación de "neoliberalismo avanzado"16. La asimetría actual entre Chile y América Latina remite a las dificultades arrastradas en la construcción de un nuevo orden político, tras el ocaso del régimen nacional-popular. La crisis del Estado de Compromiso, producto de un ascendente proceso de democratización social que desemboca en una crisis de dominación y control social, abrió una etapa en la que sucesivos intentos de ordenamiento no han logrado resolver el problema de la articulación de lo político y lo social en gran parte de América Latina. Las dictaduras representaron un proceso eminentemente defensivo y de contención en la mayoría de la región, sin las connotaciones refundacionales que ostenta la denominada "excepcionalidad chilena". Hoy en América Latina los movimientos sociales obstaculizan la constitución del orden político y social excluyente. En Chile, en cambio, se afirma un orden político basado en la exclusión y casi ausencia de actores sociales protagónicos, en donde la hondura que alcanza la transformación social y política, que por un buen lapso presenta un panorama marcado por la opacidad social mencionada, parece apuntar más bien a la constitución de nuevos actores sociales.

Ese proceso de formación ha comenzado a expresarse en las movilizaciones del último par de años, cuyos protagonistas no pueden ser reducidos -como ocurre en ciertas interpretaciones- a la figura del viejo movimiento obrero, en el caso de los nuevos asalariados, ni de los antiguos movimientos estudiantiles, en el caso de la lla-

16 Respecto a esta cuestión, puede verse Ruiz, Carlos, América Latina y la "excepcionalidad chilena”: ¿Asincronía temporal o destinos divergentes?, en Baño, Rodrigo (ed.), Chile en América Latina. Integración o Desintegración regional en el siglo XXI, Cátedra de Estudios Latinoamericanos Enzo Faletto, Facultad de Ciencias Sociales, Universidad de Chile, Santiago, 2006. 
mada "revolución pingüina"17. En el primer caso, la novedad estriba en el hecho que ciertos grupos de trabajadores subcontratistas logran formar mesas de trabajo directamente con las empresas mandantes, sobrepasando así a las empresas contratistas. De este modo, consiguen presionar por la legalización de la negociación interempresas que tan insistentemente a evitado la legislación laboral, desde su formulación originaria, en el conocido Plan Piñera de 1979. Ello vulnera un principio fundamental del modelo de crecimiento vigente, relativo a la contención del precio de la fuerza de trabajo, que vincula discursivamente las remuneraciones de los trabajadores con la productividad que aportan. En tal línea, en un ambiente competitivo, la productividad laboral aumenta, y con ella los salarios; en el entendido que cada empresa, para mantener su competitividad, requiere aumentar su productividad mediante una gestión laboral moderna. Por el contrario -se argumenta- si las empresas subcontratistas negocian de manera conjunta sus salarios frente a una mandante, o si los trabajadores negocian por rama de actividad, los salarios, en el primer caso, o los reajustes de salarios, en el segundo, tenderían a ser artificialmente similares, con independencia de la capacidad competitiva de cada empresa. Pero los trabajadores no coinciden con tal percepción de la realidad. Sus sueldos han permanecido impresentablemente bajos, en forma insostenible frente al crecimiento económico y las abultadas utilidades de las grandes empresas.

De esta forma es importante consignar que los que han aparecido no son los asalariados tradicionales; son aquellos trabajadores que dependen de los contratistas. Es decir, quienes han aparecido rebelándose recientemente, son los trabajadores constituidos a partir del modelo de crecimiento adoptado desde la segunda mitad de los años setenta hasta hoy: ese trabajo flexible, a tal punto, que ha terminado en precarización, abaratando el costo de la fuerza de trabajo, deviniendo por ello pilar fundamental de las altas tasas de crecimiento y ganancia que exhiben los rubros más dinámicos de la economía chilena en todo este tiempo.

La pregunta que salta a la vista, en definitiva, es por el grado de "modernización" al que conduce un régimen laboral como éste, el cual produce una situación en la que las empresas encargadas de la externalización de funciones carecen de márgenes para mejorar la situación de los trabajadores subcontratados; lo cual indica, a la vez, que la ganancia posible ha de obtenerse más bien a costa de la precarización de las condiciones laborales, tanto en términos contractuales como operacionales. En definitiva, se plantea un nuevo escenario frente a las formas vigentes de externalización de servicios y operaciones en las empresas, en particular a aquellas que involucran las formas más extremas de precarización del empleo. Según estimaciones en torno a un volumen que, por definición, es dificil de precisar, se trata de un universo de alrededor de 1.200.000 trabajadores en el país.

17 Para un análisis del movimiento de los estudiantes secundarios, puede verse Ruiz, Carlos, ¿Qué hay detrás el malestar con la educación?, en Revista Análisis del Año 2006. Política, Sociedad y Economía, Departamento de Sociología, Universidad de Chile, Santiago, enero, 2007. 
Es de anotar, además, que estos nuevos conflictos sociales han arrastrado consigo también al mundo de las empresas contratistas. Decir esto último es, a la vez, referirse a una parte muy importante del mundo de las PYMES, o sea, a parte importante de lo que las ciencias sociales han entendido como "pequeña burguesía”. Una pequeña burguesía que aquí aparece diferenciada de otras fracciones sociales medias, especialmente aquella numerosa que envuelve a los asalariados de "clase media"; en este caso, se trata de pequeños propietarios, aquellos que se encargan de los "negocios enanos del capitalismo".

En una sociedad -como la nuestra- con muy elevadas tasas de concentración del ingreso, estos sectores medios empresariales quedan ubicados en una condición muy dificil, marcada principalmente por la inestabilidad. De esta forma, las empresas vinculadas a lo que podríamos entender como aquella nueva pequeña burguesía, constituida a partir de la inédita proliferación del negocio de la subcontratación, que marcha de la mano del cambio de modelo de crecimiento sufrido en las últimas décadas, deviene el primer fusible que debe saltar en la misión de evitar que los trabajadores puedan negociar directamente sus demandas con las empresas ligadas a los grandes capitales. Tal condición que desempeñan las PYMES en el actual modelo, en este caso aquellas a cargo de esa "externalización de funciones" que arrojan las grandes empresas, es conocida en términos de la protección que proveen a éstas últimas ante las eventualidades propias de los ciclos de acumulación. En definitiva, lo que "externalizan" tales grandes empresas sobre las medianas y pequeñas son los costos que conlleva el acomodarse a los vaivenes económicos. Las convocan -y con ello a sus trabajadores- en los ciclos expansivos y se deshacen de ellas -y sus trabajadorescuando la demanda se contrae, dinámica en la que, en la medida en que traspasan tales costos de las oscilaciones del mercado hacia abajo, las grandes empresas prácticamente no pierden nunca. En cambio, las posiciones sociales situadas hacia abajo, cargan con la inestabilidad asociada a tales oscilaciones cíclicas.

A ello se debe agregar el hecho de tener que cargar con la presión de los trabajadores que experimentan las condiciones más precarias del mundo laboral, que son precisamente los que dependen de ellas: los trabajadores subcontratistas. Son estos trabajadores los que sostienen principalmente los bajos costos de la fuerza laboral y con ello las altas tasas de crecimiento y ganancia que registran las grandes empresas. En la mediación de tal proceso, están estas fracciones medias empresariales, esta nueva pequeña burguesía que produce el modelo de crecimiento vigente y las desprotegidas condiciones de desenvolvimiento de la fuerza de trabajo que lo acompañan. En buenas cuentas, estos sectores medios han de proteger las ganancias y altos ingresos de aquellos sectores en donde opera más marcadamente una lógica rentista, que una próxima a la modernización e innovación a menudo invocadas.

En cambio, la gran empresa, que en definitiva apela a las PYMES para protegerse, no parece vivir en una situación de capitalismo competitivo, sino más bien ampararse en situaciones de poder político - disposiciones legales dictadas a su favor-para 
asegurar altos niveles de retorno a las inversiones que realiza. No parece tener nada de casual entonces, si atendemos a esto, la escasa movilidad social que se registra en la cúspide de la pirámide social chilena; puesto en jerga sociológica: el bajo grado de apertura de la elite, o bien el grado de "cierre social" existente en este segmento, que en las últimas décadas experimenta un ritmo de ascenso en sus ingresos muy superior al del resto de la sociedad. En cambio las PYMES, y con ello esa "clase media empresarial", experimenta el vértigo de la inestabilidad de sus posiciones sociales, coincidiendo con el alto grado de movilidad social que se registra en esos segmentos de la estructura social. Si a ello se suma que son esas mismas PYMES las responsables de más del 80\% del empleo en el país, tenemos entonces un registro más amplio de la volatilidad de dichas posiciones sociales y su impacto, así como del grado en que ello se debe a la poca disposición del gran capital para entrar en las situaciones reales de competencia, en otros términos, de la indisposición del gran capital a entrar jen la dinámica capitalista!

\section{Cierre social de la elite y malestar de las capas medias}

Si apelamos a los últimos datos oficiales disponibles y comparables a partir de la homogeneidad del instrumento de medición, se tiene que -en términos de distribución del ingreso- si la distancia entre el primer y último veintil de población (5\%) en 1989 era de 137 veces, en 2003 esta distancia aumentaba casi al doble: 209 veces ${ }^{18}$. Pero tal expresión del aumento de la desigualdad en la sociedad chilena no responde tanto a un aumento de la pobreza, sino más bien ocurre todo lo contrario, el sector que se despega del resto de la sociedad es el de mayores ingresos. Tal distanciamiento se produce no sólo respecto del veintil más pobre, sino que, aunque en diferentes magnitudes, sobre todo el resto de la sociedad chilena, revelando que el carácter distintivo que asume la desigualdad en la sociedad chilena actual estriba, a diferencia de antaño, en el agudo proceso de concentración del ingreso experimentado en los últimos tres lustros que corresponden al período democrático.

Estos números están diciendo que no sólo los sectores más pobres han quedado excluidos de la fiesta del crecimiento económico en todos estos años, sino también los trabajadores estables e incluso las propias clases medias, incluyendo a muchas de sus capas más acomodadas. De ahí que, al malestar continuo de los pobres y los trabajadores, se ha empezado a sumar, de modo gradual pero ascendente, el malestar de estos sectores medios. Comienza a aflorar un malestar mesocrático, que le imprime nuevos rasgos al más conocido malestar popular con el patrón de crecimiento económico vigente y el modelo de sociedad a él asociado.

$18 \quad$ Para estas y otras referencias sobre el panorama de la desigualdad en Chile, y su comparación con otros países de la región y el mundo, véase Ruiz, Carlos, ¿Habrá crecimiento con igualdad para el Bicentenario?, en Revista Análisis del Año 2004. Política, Sociedad y Economía, Departamento de Sociología, Universidad de Chile, Santiago, enero, 2005. 
La sostenida expansión de las clases medias en todos estos años es, por tanto, un mito; ya que en la medida en que a dichas clases se les considera habitualmente asociadas a la estabilidad de la democracia y el desarrollo, entonces no es dificil comprender que se trata de un mito ideológico, que busca efectos políticos. Por lo que, si se tiene en cuenta que lo que ocurre no es nada de eso, sino más bien la aparición de un sector con aguda conciencia de que está excluido de las riquezas que genera el crecimiento económico y que no encuentra medios efectivos para acceder a él, se puede concluir entonces que el aumento del malestar de estos sectores medios constituye un riesgo para la estabilidad política acaso más sensible que el que han expresado los sectores más pobres, así como los trabajadores.

En 1997, el año más álgido en cuanto a conflictos sociales del período democrático antes de la "revolución pingüina", concentró las fuertes protestas de los trabajadores del carbón, de los puertos, de la educación básica, de mapuches y estudiantes. Todo ello con un claro carácter popular en las decenas de miles de personas que entonces se movilizaron. En cambio el 2006, detrás de la protesta de los secundarios apareció, además de los sectores ya conocidos en los últimos conflictos sociales, el malestar mesocrático. Y quedó claro que, con su apoyo, le imprimió connotaciones nuevas al conflicto social, especialmente en término de proyecciones políticas. Es que el malestar mesocrático remite a la insatisfacción del sector más influyente en la configuración cultural del país durante la mayor parte del siglo pasado, que constituye en gran medida las imágenes, idearios y expectativas de los propios sectores populares. De ahí la complejidad que reviste para este tipo de regímenes políticos el malestar de las clases medias.

Los dilemas anotados remiten, en definitiva, a los grados de seguridad y certeza existentes en la población, o bien a sus déficit y, como tal, a la incertidumbre. Se trata de una inseguridad socioeconómica y psicosocial, que en parte se explica por el carácter y la orientación que asumen las transformaciones económicas e institucionales de las últimas décadas, y se manifiestan en lo que el PNUD apuntó como la existencia de una sociabilidad y comunicación deficitaria en la sociedad chilena ${ }^{19}$. Tiene que ver con la relevancia que alcanzan los sentimientos de pérdida de protección social ante la dirección privatizadora que asume la transformación de los sistemas de salud y previsional, así como con las dificultades que se surgen en torno a la realización de oportunidades, y la forma en que éstas se expresan en ámbitos como la educación, el trabajo y el consumo. De ahí la impresión de que la seguridad humana resulta deficitaria en un Chile en pleno y acelerado proceso de modernización.

Mientras que las oportunidades de empleo aumentan con el crecimiento económico, tal incremento no ha sido igual para los diversos sectores de la sociedad. Los grupos con menor capital social y cultural tienen también menores oportunidades 
de insertarse en un proceso de modernización que se apoya cada vez más en el conocimiento y la información. La mayor demanda de empleos calificados en la llamada "sociedad del conocimiento" sugiere que la flexibilidad del empleo seguirá aumentando en el futuro, incrementando las oportunidades y los riesgos. En tal caso, el problema prioritario consistirá en la adaptación de las personas a una fuerte rotación del empleo. Nuestra criolla versión, a fin de cuentas, de la mentada "sociedad del riesgo".

En términos de ingresos, en los años noventa no sólo se recuperan los niveles anteriores, sino que tiene lugar una mejoría de los ingresos en todos los sectores sociales; aparecen nuevos empleos que permiten un aumento de los ingresos, pero éstos quedan rezagados en relación con el crecimiento de los ingresos del país en su conjunto. La percepción de la distancia que separa los ingresos propios de los de otros sectores y la comparación de la situación propia con el crecimiento económico sostenido del país acentúan el sentimiento de injusticia de amplios grupos sociales. Ello remite a los problemas de ascenso social que son, tradicionalmente, un motivo de preocupación de los chilenos. La mayor flexibilidad del mercado laboral se acompaña de una mayor segmentación entre las categorías sociales. La movilidad resulta más bien horizontal que ascendente.

A su vez, dada la alta relación entre ingreso y educación, se ha impregnado en el sentido común una creciente valoración por la educación y la capacitación. De ahí que el malestar con la educación resulte también un malestar con la movilidad y la falta de equidad. En cambio, en el caso de los empresarios y ejecutivos, los ingresos parecen depender menos de la educación que de la experiencia y de otros factores como el acceso a activos fijos. En definitiva, los ingresos ya no se refieren a una escala institucional de remuneraciones y tienden a depender mucho más de la inserción en redes; dos personas con similar formación pueden tener muy distintos ingresos según su "valor" circunstancial en determinada coyuntura. En tales contextos, los ingresos suelen ser más altos, pero también más inestables. Es decir, la posición laboral y los ingresos devienen situaciones aleatorias que frecuentemente dependen más de factores externos que de méritos propios.

En suma, la rápida reorganización y tecnificación del trabajo aumenta las oportunidades y los riesgos. En el futuro, el mercado laboral seguramente estará marcado por una fuerte rotación. Habrá más oportunidades de empleo, particularmente para personas calificadas, pero el empleo será más inestable. El problema prioritario ya no es la estabilidad del empleo actual, sino el permanente proceso de reinserción en un mercado extraordinariamente móvil. El futuro aparece pues como algo incierto en un aspecto tan vital como lo representa el trabajo. Aun cuando tal dinámica no provoque necesariamente desempleo, suscita incertidumbre. En este sentido, cabe 
interrogarse por el significado político que puedan tener los sentimientos de inseguridad, desamparo y desencanto que se aprecian en la sociedad.

Ello apunta a los requerimientos que pesan sobre la democracia chilena; requerimientos culturales propiamente tales, pero capaces de afectar al propio sistema político. Tales requerimientos culturales actúan como un malestar con la política, en la medida en que, en la actualidad, los anhelos no encuentran un marco interpretativo y, por lo tanto, tras las crisis ideológicas recientes, se produce la ausencia de todo proyecto. Con ello, aunque fértil para el problema del orden, el sentimiento que subyace a la democracia actual es de desencanto. Mientras, la política, y el análisis de ésta, se centra en la dinámica institucional, en la estrategia de los actores y los condicionamientos económicos, sin considerar debidamente la experiencia diaria de la gente, sus miedos y sus deseos.

En la medida en que las organizaciones políticas, cada vez más especializadas y escindidas del quehacer diario de la gente común, ya no crean ni aseguran las identidades colectivas, éstas tienden a recomponerse al margen e incluso en oposición a las instituciones. Pero también decaen aquellos ámbitos de sociabilidad informal en que se compartían emociones y sueños, que se constituían referentes colectivos. Ello lleva a una escisión entre el ámbito cotidiano y la sociedad general. Una oposición entre "comunidad" (no destruida por la modernización) y la "sociedad" orientada por la racionalidad formal. El aspecto más relevante de la vida cotidiana se vuelve, entonces, la búsqueda de las certezas más básicas. Esta escisión entre lo cotidiano/comunidad y política/sociedad está en el origen de la pérdida de seguridad que experimentan los individuos.

El punto es que el malestar con la política plantea el dilema de restablecer cuál es el campo de la política. En un contexto como el actual de vertiginosas mutaciones culturales, expresión de una crisis de identidad, ¿̇en qué medida contribuye esto entonces a generar una cultura política democrática? Al contrario, la crítica a la noción histórica de sujeto tiende a socavar las bases para repensar la política. Al identificar la lógica política con el mercado y el intercambio no puede plantearse el problema de la identidad. Pero esta es una de las mayores tareas pendientes que enfrenta la cultura política democrática. De ahí la importancia de la cultura política: si no se logra desarrollar un nuevo horizonte de sentidos la institucionalidad democrática queda sin arraigo, como una cáscara vacía.

Mientras tanto, la elite económica permanece ajena a estas preocupaciones y los dilemas de extensas franjas de la sociedad. A pesar de que el país no logra retomar la anhelada senda del crecimiento, las más grandes empresas han gozado de ganancias a tasas mucho más altas que la del crecimiento del país. Las disputas no pasan de ajustes internos que ratifican, sin sorpresa, el predominio de las líneas bancaria y minera den- 
tro del empresariado. El cambio más relevante en los últimos años es la adopción de una línea pragmática, que lleva al empresariado a distanciarse de la figura de Pinochet y llegar a crecientes acuerdos con la Concertación, o más exactamente con su elite "transversal". La apertura de los directorios de sus empresas a un selecto grupo de tecnócratas y figuras políticas de esa elite concertacionista, se suma al trabajo conjunto que emprenden en esferas internacionales para viabilizar acuerdos y alianzas con capitales externos.

Presenciamos la consumación de la alianza de la elite concertacionista y el muy empresarial Centro de Estudios Públicos (CEP), una suerte de "dirección intelectual y moral de la sociedad", de cuyas oficinas han salido en los últimos años los diseños de gravitantes políticas públicas. Invariable ha sido el ritual de comentar y discutir en el poderoso centro con los grandes empresarios y sus técnicos cuanto plan de significación tiene el gobierno de turno. Se consolidan así, al punto del rito, tales encuentros y su eficacia para cimentar una estrecha vinculación entre la elite política y económica del país ${ }^{20}$.

Claro que no toda la elite resulta históricamente estática. A pesar de recomposiciones periódicas, la elite dirigente, por siglos, no varió en lo medular. Pero es cierto que esta situación colapsa con la reforma agraria de los años sesenta y setenta del siglo recién extinto, y el viejo patriciado señorial desaparece para siempre. Se termina con la hacienda y el inquilinaje que antaño brindaban un aura de casta impenetrable, a menos que se aportara dinero, influencia política o solvencia profesional, los medios clásicos de ascenso del viejo Chile.

Pero ello no puede desconocer los cambios que en la última etapa experimenta la elite chilena. Cambian las formas de hacerse y hacer visible la riqueza. En razón de que ésta posee ahora un acentuado componente financiero, se vuelve exponencial. Si antes, bajo códigos estamentales estrictos que valoraban más los privilegios que la mera cuantía de dinero a su haber, se requerían dos o tres generaciones para ser aceptado, hoy se puede ser multimillonario en menos de una década. Para hacerse una idea de esta nueva realeza, se puede considerar que las fortunas sobre el millón de dólares -entre emergentes y consolidadas- abarcan hoy en Chile a unas 4 mil familias. De ellas, sólo 632 superan los 5 millones de dólares. Tan acentuado resulta el fenómeno que comparaciones internacionales arrojan que pocos países en el mundo exhiben fortunas tan cambiantes como Chile. Los profundos cambios económicos, políticos y sociales que vive el país durante las últimas décadas han influido enormemente en los

20 El Informe del PNUD de 2004 presenta un detallado mapa de los vínculos existentes entre las distintas elites -económicas, políticas, culturales, etc.- y el carácter cerrado que estos adoptan.Véase PNUD, El poder: ¿para qué y para quién?, Informe de Desarrollo Humano en Chile, Santiago, 2004, parte 5, La elite chilena y la difícil conducción del desarrollo. Allí se afirma que, entre las entidades que más propician el actual entramado de la elite chilena se encuentran -sin nombrar alguno en especial- los centros de investigación, confirmando su creciente funcionalidad para los objetivos de la elite, p. 200. 
vaivenes de la riqueza y de quienes la detentan. Después de la reforma agraria, donde parte importante de la elite de ese entonces perdió su fuente de riqueza, surgieron después de 1973 nuevos grupos económicos, varios de los cuales colapsaron durante la recesión de los años ochenta, protagonizando un abrupto reordenamiento del "mapa de la extrema riqueza".

De ahí que un corte de 10\% de la población de mayores ingresos -empleado a menudo en investigaciones con estos fines- resulte aún demasiado grueso para perfilar a este sector. Una familia chilena en la que el marido gana 800 mil pesos y la esposa 400 mil y tiene al menos un hijo, se ubica inmediatamente en el 10\% de mayores ingresos. Cohabita en dicho decil con los millonarios antes anotados, y hasta fortunas que superan los mil millones de dólares. Tal disparidad revela la alta heterogeneidad de ingresos que convive en el 10\% más alto de la pirámide social chilena. En el 90\% restante, según la encuesta Casen 2003, se congregan desde la pobreza extrema hasta sectores medios bajos. La verdadera riqueza en Chile está asentada en el 1\% de la población, aunque éste también resulta aún relativamente heterogéneo.

Como se sabe, la explosión de la tenencia de bienes en Chile ha sido sostenida y generalizada. Precisamente, uno de los mayores cambios de la sociedad chilena es que la tenencia de bienes dejó de ser un buen indicador para diferenciar a los grupos sociales. El consumo se ha expandido socialmente, con lo que muchos bienes perdieron su etiqueta de exclusividad. No obstante, la elite mantiene sus propios códigos de estatus que le permiten diferenciarse. Aunque la adquisición de bienes en los mercados de alto lujo podría ser la muestra más evidente de ello, según quienes estudian estas pautas, se mantienen ciertas constantes históricas, como el número de personas que trabajan alrededor de las tareas familiares y el lugar donde se estudia, se vive o se veranea.

Se produce entonces, un tipo de acción colectiva de parte de la elite chilena que busca asegurar los máximos beneficios posibles, limitando a otros el acceso a los recursos y oportunidades, algo que en sociología se conoce como cierre social de la elite ${ }^{21}$. Ello considera la necesidad de designar ciertos atributos sociales o físicos como bases justificativas de tal exclusión, con la finalidad de monopolizar determinadas oportunidades, normalmente económicas. Su intención es siempre cerrar el acceso a oportunidades sociales y económicas. La monopolización no sólo las oportunidades sino del prestigio social como tal resulta indicativa de ello. Por esto, no ha de extrañar que la elite chilena resulte hoy menos permeable y se defienda para que no entre más gente al grupo.

Empero, a instancias de esa misma elite, se divulgan las promesas liberales acerca de que los bienes escasos, como el poder, el prestigio o la propiedad, deben distribuirse al compás del desempeño y del talento de los ciudadanos y no en base a características

21 Véase Parkin, Frank, Orden político y desigualdades de clase. Estratificación social de las sociedades capitalista y comunista, Editorial Debate, Madrid, 1978. 
adscritas, como el origen familiar. Por eso, desde hace casi dos siglos, la escuela tiene un lugar preponderante entre las instituciones sociales. A la mezcla de ambas cosas (igualdad de derechos y distribución de recursos en base al desempeño) se le suele denominar meritocracia. Un tipo de sociedad en la que los recursos se distribuyen según los logros obtenidos por cada uno de sus miembros. Pero la nuestra no parece una sociedad meritocrática. En vez de distribuir recursos escasos en base al mérito o al desempeño, se hace en base a cualidades adscritas como la cuna, las confianzas tejidas en los colegios, las redes familiares, el ascenso matrimonial, las similitudes construidas a la salida de la misa dominical, las adscripciones religiosas. Intervienen muchos criterios para distribuir bienes escasos y para decidir quién está por arriba y quién por debajo en la escala del prestigio y del poder. Así, la voluntad y el esfuerzo personal se hacen irrelevantes.

\section{La política ensimismada}

En términos tanto de la formación de nuevos actores sociales como de la capacidad de procesamiento de conflictos del sistema político, un aspecto a considerar, de mucha relevancia en el panorama actual, es el de la respuesta tecnocrática con que se enfrentan muchas de las movilizaciones y malestares sociales emergentes en el último tiempo. La rígida separación de lo político y lo social, como dimensión constitutiva tanto del sistema político actual, así como del modelo de orden social vigente, es reafirmada por la irrupción más reciente de las movilizaciones de los trabajadores subcontratados. El apoyo concitado a sus demandas por parte de parlamentarios pertenecientes a la coalición gobernante, y su consiguiente crítica a las autoridades involucradas, desencadenó el reproche de varios constitucionalistas. Además de acusar tal acción de inconstitucional, amenazaron con demandar la inhabilidad de los parlamentarios en cuestión, un comportamiento que -según tal enjuiciamiento- podría llegar a ser sancionado por el Tribunal Constitucional, debido a la indicación expresa de la Carta Magna, en orden a que los parlamentarios han de abstenerse de actuar a favor de alguna de las partes en cualquier conflicto sindical o estudiantil, ya sea al interior de empresas privadas o públicas.

La idea es que la Constitución plantea una serie de mecanismos para evitar que los partidos políticos “monopolicen” la representación ciudadana, y trazar así una distancia rígida entre la representación política y la de cuerpos intermedios como gremios y sindicatos. Como se ha señalado en múltiples ocasiones, el principio rector de dichas normas es el de evitar los mecanismos de procesamiento de conflictos sociales propios del viejo Estado de Compromiso. En otras palabras, se trata de evitar el retorno a los viejos mecanismos en los que se involucraba directamente el Estado y se producía, con ello, una relación directa de los partidos políticos con los actores sociales, interviniendo ambas esferas en la promoción de éstos últimos al tiempo que, como consecuencia 
de ello, los propios partidos políticos asumían con mayor transparencia un carácter sectorial o social determinado. Hoy, en cambio, bajo este principio, se apuesta a un distanciamiento entre lo social y lo político (brecha que exceptúa al sector empresarial), a través -entre otras formas- de un régimen de prescindencia estatal en materia de regulación de relaciones sociales. Un régimen de "abstinencia" estatal que suele expresarse a través de la reiterada mención de las autoridades acerca de que "el Estado no interviene en conflictos entre privados".

En este mismo sentido, el empresariado sitúa como máxima crítica ante todo el panorama de conflictos vividos en este año, el hecho que se reinstalara de cierto modo el viejo sistema "tripartito" (empleados, empleadores y Estado), al involucrarse la empresa estatal (Codelco) en un conflicto que, a su juicio, debió mantenerse precisamente entre "privados" y de forma descentralizada, esto es, entre las empresas contratistas y los trabajadores subcontratistas de cada una de ellas dependiente, en forma separada. La no intervención de esferas estatales -y de partidos políticos así como parlamentarios también- constituye en definitiva una despolitización inducida en las relaciones sociales que están en la base de la sociedad, e intenta evitar que los conflictos sociales adquieran alguna connotación política al buscar mantenerlos en una estrictamente economicista, y con ello corporativa.

Como no es difícil de advertir, esta coincidencia entre el "espíritu de las leyes", la disposición estatal y la preocupación empresarial alude, en definitiva, al carácter social de estas dimensiones de lo político. Uno que explica en no poca medida los extremos niveles de concentración del ingreso que caracterizan a la sociedad chilena en las últimas décadas, el que vuelve a ser consignado por la Encuesta Casen más reciente. Continúa en operación esa cada vez más aparente "paradoja" de la coincidencia de los procesos de disminución de la pobreza y aumento de la desigualdad. La pobreza ha seguido descendiendo -la pobreza estadística, claro está- a un ritmo, sin embargo, que se ve menguado a medida en que se entra en la llamada "pobreza dura", marcada por la abierta carencia de mecanismos de integración social. En cambio, en cuanto a la cuestión de la desigualdad, va quedando cada vez más claro lo poco efectivo que resulta considerar a este fenómeno a partir de comparaciones relativas al de mayores ingresos. El porfiado aumento de la desigualdad se representa en toda su condición al considerar franjas elitarias bastante menores de la sociedad chilena: ahí, entonces, su curso de distanciamiento del resto de la sociedad chilena no cesa. 